\title{
Prediction of Curling Distance of Dry-Relaxed Cotton Plain Knitted Fabrics
}

\section{Part 1 : Theoretical Analysis of Moments on the Loop that Force the Fabric to Curl}

\author{
Nuray Ucar* \\ Istanbul Technical University, Faculty of Mechanical, Textile Engineering Department, Taksim, Istanbul, TURKEY \\ *Current Address: Georgia Institute of Technology, 801 Ferst Drive, School of Textile \& Fiber Engineering, \\ Atlanta, Georgia, 30332-0295, USA
}

Received 9 December 1999 ; accepted for publication 29 September 2000

\begin{abstract}
Prediction of curling distance of dry-relaxed cotton plain knitted fabric has been realized by using multiple regression analysis. One set of the parameters that are used in the multiple regression analysis is the moments on the loop that force the fabric to curl. There have been several studies of the moments on the loop, but the models developed are too complex for practical use. Thus; in the present study, moments on the loop have been determined by means of Castigliano Theorem, which leads to a more usable model. The following results have been obtained:

(1) Simple formulas for the moments, $M_{y}$ and $M_{x}$. These formulas depend on fabric and yarn parameters, such as course-wale spacing, yarn diameter and bending rigidity of yarn. $\mathrm{M}_{\mathrm{y}}$ is the moment that affects the bending and sidecurling behavior around the oy axis (Figure $5 \mathrm{a}$ ). $\mathrm{M}_{\mathrm{x}}$ is the moment that affects the bending and top/bottom-curling behavior around the ox axis (Figure $5 \mathrm{a}$ ).

(2) Good agreement between $M_{y}, M_{x}$ as presented and those proposed by Postle and Munden was observed [11] ( $M_{y}$ : $0.0367 \mathrm{~g} \mathrm{~cm}^{-0} 0.04 \mathrm{~g} \mathrm{~cm}$ and $\left.\mathrm{M}_{\mathrm{x}}: 0.1896 \mathrm{~g} \mathrm{~cm}-0.175 \mathrm{~g} \mathrm{~cm}\right)$.

(3) Equations 20,23, 25 and Table 1 and also previous studies $[1,2,4,5,7,8,10,11]$ show that the values of $\mathrm{M}_{\mathrm{y}}$ and $M_{x}$ increase as the tightness factor and bending rigidity of yarn increase. The values of moment around ox axis, $M_{y}$, are higher than those around oy axis, $\mathrm{M}_{\mathrm{y}}$.
\end{abstract}

